Revista Grifos - Unochapecó

\title{
CONTRIbUiÇão da ECONOMIA SOLIDÁRIA NAS EXPERIÊNCIAS DA ASSOCIAÇÃo dO Movimento de Mulheres Camponesas de Riacho de SANTANA-BAHIA-Brasil
}

\author{
CONTRIBUTION OF SOLIDARY ECONOMY IN THE EXPERIENCES OF THE ASSOCIATION OF \\ the Peasant Women's Movement of Riacho de Santana-Bahia-BrazIL
}

\section{CONTRIBUCIÓn DE LA ECONOMÍA SOLIDARIA EN LAS EXPERIENCIAS DE LA ASOCIACIÓN Del Movimiento de Mujeres Campesinas de Riacho de SANTANa-BaHia-Brasil}

\author{
Bárbara Lourena de Sousa Santos Oliveira ${ }^{1}$ \\ ORCID: https://orcid.org/0000-0001-7126-3578 \\ Rita Vieira Garcia ${ }^{2}$ \\ ORCID: https://orcid.org/0000-0002-2142-1766 \\ Jessica Ferreira Lima ${ }^{3}$ \\ ORCID: https://orcid.org/0000-0001-9123-7916
}

Submissão: 25/04/2020 / Aceito: 25/08/2020 / Publicado: 30/06/2021.

\begin{abstract}
Resumo
O presente trabalho tem a pretensão de demonstrar como as aprendizagens vivenciadas nas práticas do movimento social de mulheres e da Economia Solidária contribuíram com a inserção de mulheres camponesas nos espaços organizativos e produtivos no contexto da AMMCRS. O texto traz o perfil das mulheres e a trajetória da Associação visando à contextualização da situação e os processos desenvolvidos com as práticas, cogitando-os como elementos construtores socioeducativos. A metodologia adotada se insere no campo da pesquisa qualitativa exploratória junto com uma pesquisa-ação usando os seguintes instrumentos: roda de conversa, mapa falado, questionário e entrevista. Os resultados sugerem que as práticas da autogestão, do comércio de ciclo curto, as relações entre associadas e parcerias, além das reuniões na Associação contribuíram com o desenvolvimento pessoal e coletivo, social e político das mulheres na Associação como também com o fortalecimento da Economia Solidária localmente.
\end{abstract}

Palavras-chave: Associativismo. Comércio solidário. Agricultura familiar.

\begin{abstract}
The present work intends to demonstrate how learning experiences in the practices of the social movement of women and Solidarity Economy contributed to the insertion of growers women in the organizational and productive spaces in the context of the AMMCRS. The text presents the profile of women and a trajectory of the Association aiming at

\footnotetext{
1 Especialista em Inovação Social ênfase Economia Solidária e Agroecologia. Atua como Agente de Desenvolvimento Territorial. Seplan-Bahia. E-mail: barbarariacho@ hotmail.com

${ }^{2}$ Doutora em Ciência e Tecnologia de Alimentos. IFBaiano. Grupo de Pesquisa em Agroecologia IFBaiano. E-mail: rita.garcia@ifbaiano.edu.br

${ }^{3}$ Bibliotecária e Documentarista. MBA em Gestão da Informação e do Conhecimento. Atuação em Ciência da Informação. IFBaiano. E-mail: jessica.lima@ifbaiano.edu.br
} 
contextualization of the situation and the processes developed with the practices considered as building elements socio-educational. The adopted methodology is inserted in the field of qualitative exploratory research along with action research using the following instruments: round of conversation, spoken map, questionnaire and interview. The results suggest that the practices of self-management, short-cycle trade, the relationships between associates and partnerships, the meetings in the Association, contributed to the personal, collective, social and political development of women in the Association and to the strengthening of the Economy Solidary locally.

Keywords: Association. Solidary trade. Family farming.

\section{Resumen}

El presente trabajo pretende demostrar como las experiencias de aprendizaje en las prácticas del movimento social de mujeres y la Economía Solidaria contribuyeron a la inserción de las mujeres campesinas en los espacios organizativos y productivos en el contexto de AMMCRS. El texto presenta el perfil de las mujeres y la trayectoria de la Asociación para contextualizar la situación y los procesos desarrollados junto con las prácticas, considerándolas como elementos constructores de los procesos socioeducativos. La metodología adoptada se inserta en el campo de la investigación cualitativa exploratoria junto con una de tipo investigación-acción utilizando los siguientes instrumentos: circulo de conversación, mapa hablado, cuestionario y entrevista. Los resultados sugieren que las prácticas de autogestión, el comercio de ciclo corto, las relaciones entre asociadas y asociaciones, y las reuniones del movimento, contribuyeron al desarrollo personal y colectivo, social y político de las mujeres en la Asociación, así como al fortalecimiento de la Economía Solidaria local.

Palabras chave: Associaciones. Comercio solidario. Agricultura familiar.

\section{INTRODUÇÃO}

Economia Solidária (EcoSol) e seus processos socioeducativos são tematizados neste artigo, que é fruto de um Trabalho de Conclusão de Curso da Pós-Graduação em Inovação Social com ênfase em Agroecologia e Economia Solidária do Instituto Federal Baiano campus Bom Jesus da Lapa realizado pela autora primeira do presente texto.

O trabalho foi desenvolvido no contexto da Associação do Movimento de Mulheres Camponesas de Riacho de Santana (AMMCRS) - um empreendimento solidário fundado a partir do incentivo de militantes do Movimento de Mulheres Camponesas (MMC) no município baiano Riacho de Santana. Esse contexto contém em si uma diversidade de componentes imbricados - movimento social, agroecologia, questões de gênero, políticas públicas, entre outros. A abordagem foco do artigo, no entanto, se assenta nos processos educativos com a EcoSol sem, contudo, negar a importância dos demais fatores no processo. 
O MMC é um movimento social autônomo, democrático, popular, agrega mulheres do campo pertencentes à classe trabalhadora que lutam pela causa feminista e pela transformação da sociedade incluindo na pauta a produção de alimentos saudáveis, construção de um projeto de agricultura ecológico e libertação da mulher (MMC 2014).

O trabalho tem a pretensão de demonstrar como as práticas vivenciadas com a EcoSol contribuíram com a inserção de mulheres camponesas nos espaços organizativos e produtivos bem como com o crescimento pessoal e coletivo, social e político das mesmas. Procurou-se compreender se houve aprendizagens e transformações na vida das mulheres a partir da atuação na AMMCRS, representado aqui como o chão da EcoSol. Para auxiliar no entendimento, uma indagação faz-se necessária: de que forma as mulheres da AMMCRS, atuando com práticas da EcoSol, contribuíram com a formação e o desenvolvimento do grupo? O texto com os dados levantados durante a pesquisa-ação tem um caráter de descrição contextualizada relacionando-o ao aporte teórico. O trabalho está apresentado em quatro tópicos: o perfil das mulheres participantes da AMMCRS (1), a trajetória da AMMCRS (2), processos educativos desenvolvidos nos espaços da prática com EcoSol (3) e aprendizados gerados a partir da pesquisa-ação com foco na qualificação da produção e apresentação dos alimentos (4).

Processos educativos, aqui, devem ser entendidos como os saberes gerados nas relações que acontecem nas experiências da EcoSol. Tratar a EcoSol como processo educativo tem acordo com o pensamento de Singer (2002, p. 19, grifo nosso) “A economia solidária é um ato pedagógico em si mesmo, na medida em que propõe uma nova prática social e um entendimento novo dessa prática. A única maneira de aprender a construir a economia solidária é praticando-a". Não há fórmulas ou procedimentos a serem seguidos. Dubeux e Batista (2017) sinalizam que a prática dos sujeitos se dá de maneira diversa e conforme o contexto sócio-político, econômico e cultural de cada território.

Borges e Sguarezi (2012) mencionam que a multiplicidade de atores e sua diversidade cultural, política e econômica produzem saberes, podendo ser considerado como um processo educativo por possibilitar a construção de conhecimento desde a mobilização coletiva até a organização gerencial do empreendimento. Cabral (2005) também reconhece a essência pedagógica da EcoSol que se configura como um instrumento de formação humana, um lócus de construção de saberes a partir do dialógico entre o meio físico e social. 
A EcoSol pode apresentar três dimensões. É uma atividade econômica de produção, oferta de serviços, comercialização, finanças ou consumo baseada na democracia e na cooperação. Apresenta componentes simbólicos e de valores, por envolver uma mudança de paradigma, da competição para a cooperação, e da inteligência coletiva, livre e partilhada. Tem dimensão política, por ser um movimento social que luta por uma forma de desenvolvimento construído a partir da solidariedade, democracia, cooperação, preservação ambiental e dos direitos humanos. A sua essencialidade reside na articulação dessas três dimensões (TYGEL, 2011).

A EcoSol tem caráter de atividade econômica com um nexo diferente da lógica de mercado e do Estado pois tem como base da organização os fatores humanos, favorecendo relações cujo laço social é valorizado pela reciprocidade e adota formas comunitárias de propriedade (LAVILLE; GAIGER, 2009).

Os empreendimentos na EcoSol são caracterizados pela propriedade coletiva dos meios de produção, não há empregados vendendo sua força de trabalho; as decisões são tomadas nas assembleias, não há divisão entre quem pensa e quem opera, quem comanda e quem obedece; não há lucro para o proprietário do capital, que pode receber o excedente como remuneração do capital investido igual aos demais que têm acesso a esse excedente (GAIGER, 2007).

As diversas formas de expressões como coletivos de geração de renda, redes e clubes de troca, grupos de produção ecológica, associações de mulheres, serviços de proximidade, entre outros, apresentam em comum a primazia da solidariedade, o que acontece pela socialização dos recursos produtivos e a adoção de critérios igualitários (LAVILLE; GAIGER, 2009).

Em tese, a EcoSol se contrasta com a economia capitalista porque redefine o centro da atividade econômica, do capital para o trabalho, da maximização do lucro para o preço justo, da hiperespecialização para a politecnia, da competitividade abusiva para a solidariedade, reformando a atual lógica centrada no consumismo e recolocando nas dimensões social, ética, cultural, ambiental e política (BORGES; SGUAREZI, 2012).

A partilha desta experiência, cogitando as práticas nos espaços dos movimentos sociais como elementos construtores nos processos socioeducativos, pode ser útil para os agentes políticos e pedagógicos quando forem planejar ou (re)pensar a formação e preparação de grupos de EcoSol. 


\section{Metodologia}

A Associação do Movimento de Mulheres Camponesas de Riacho de Santana Bahia (AMMCRS) - contexto deste trabalho situa-se no município Riacho de Santana, pertencente ao Território de Identidade Velho Chico, localizado na Região Sudoeste da Bahia, distante $720 \mathrm{Km}$ da capital e, conforme dados censitários, possui uma área de $3.183,911 \mathrm{~km}^{2}$, população estimada de 35.421 pessoas e Índice de Desenvolvimento Humano Municipal 0,615 (IBGE, 2010).

O referencial metodológico adotado se insere na perspectiva de uma pesquisa qualitativa exploratória aliada a uma pesquisa-ação que teve foco na qualificação para manipulação e apresentação dos alimentos processados na AMMCRS, especialmente boas práticas, embalagem e rotulagem. A coleta de informações se deu no período de janeiro a dezembro 2017 por meio de consulta a documentos, reuniões específicas para fins da pesquisa, visitas às famílias, fazendo uso dos instrumentos roda de conversa, mapa falado, questionário e entrevista. O grupo foi selecionado com base no interesse e disponibilidade das sócias em participar da produção de dados.

O método qualitativo pesquisa-ação envolve a resolução de problemas mediante ações planejadas com os sujeitos. O pesquisador participa na tomada de decisão, na análise da realidade e parte da suposição da elaboração e o desenvolvimento do conhecimento teórico intencionando solucionar problemas (THIOLLENTE, 1988). Os sujeitos são mobilizados para atuar no processo da investigação e identificação das características de realidade pesquisada, implementar e avaliar as ações numa relação de ação e reflexão. A pesquisa-ação comporta simultaneamente os aspectos explicação, aplicação e implicação (VERGARA, 2005).

O texto que segue foi um esforço em situar as participantes deste estudo no seu contexto social, enquanto mulheres camponesas da agricultura familiar moradoras do semiárido, no nordeste do país, e tornar evidente a aproximação com as propostas da Ecosol a partir de uma reflexão teórica.

\section{Resultados E Discussão}

De uma maneira geral, os resultados sugerem que os espaços das práticas da EcoSol contribuíram com o desenvolvimento pessoal e coletivo das mulheres na AMMCRS. As 
práticas da autogestão, do comércio de circuito curto, as relações entre as associadas e com as parcerias, os encontros e reuniões do movimento, entre outros, foram responsáveis pela formação e aprendizado dessas mulheres. Faz-se necessário colocar, mesmo não sendo foco deste artigo, que a atuação das mulheres com experiências agroecológicas ajudou no processo de construção e fortalecimento de resistências ao modelo convencional de produção e de comercialização de alimentos.

\section{Perfil das mulheres sócias da AMMCRS}

A Associação é formada por 114 mulheres, camponesas, agricultoras, feirantes, que produzem alimentos para o consumo da própria família e que atuam nas atividades da AMMCRS. Todas são responsáveis por atividades domésticas e pelo cuidado com os filhos, esposo e, muitas vezes, com outros familiares. Do quantitativo de associadas, 100 mulheres participam com mais frequência dos projetos e ações da Associação e as demais (14 mulheres) hesitam preferindo realizar atividades fora da Associação por, talvez, ainda não acreditar no potencial de trabalho em grupo.

O grupo tem faixa etária entre 20 a 70 anos. A maioria (102 mulheres) é casada e demais, separadas ou viúvas. As famílias são compostas por, em média, quatro a cinco pessoas. O nível de escolarização varia do ensino Fundamental I, alfabetizada pelo Programa Todos Pela Alfabetização (Topa) ${ }^{4}$ e duas graduandas nos cursos tecnológicos em Agroecologia e Nutrição.

O tamanho da área do terreno pertencente às mulheres varia de um a dezesseis hectares. As proprietárias mais envolvidas nas atividades da AMMCRS possuem renda de meio a dois salários mínimos, além do benefício do programa Bolsa Família. Todas possuem a Declaração de Aptidão ao Programa Nacional de Fortalecimento da Agricultura Familiar individual.

O perfil socioeconômico das mulheres da AMMCRS se aproxima da realidade de outras comunidades rurais. Na categoria dos camponeses encontram-se mulheres com baixíssimo nível de vida e que têm a sobrevivência como principal preocupação. O mundo do trabalho se confunde com o da família, que é a unidade de produção econômica e social. A comunidade é um prolongamento da família. O tempo é dividido entre as tarefas na roça,

\footnotetext{
${ }^{4}$ Programa de alfabetização do governo da Bahia e parcerias para jovens (acima de 15 anos), adultos e idosos nãoalfabetizados.
} 
em casa, no cuidado dos filhos e noutras tarefas familiares e sociais, não sobrando tempo para si. Ainda que enfrentando a dura realidade da vida rural, precisam se engajar, cada vez mais, na luta dos trabalhadores rurais, pelo direito de existir como cidadão e de viver (FERNANDES, 1985).

O quadro descrito acima ainda é uma realidade em tempos mais recentes apesar dos avanços. Cardoso e Rodrigues (2009) relatam, a partir de reflexões de experiências com mulheres, que a falta de valorização e visibilidade do trabalho, a não divisão dos afazeres domésticos acabam gerando sobrecarga e comprometendo a participação nos espaços públicos (sindicatos, associações, movimentos), além do trabalho reprodutivo.

Silva (2016) registra que as mulheres aparecem como sujeitos importantes na luta pela transformação social, preservação do meio ambiente e da cultura dos povos camponeses e tradicionais, contribuindo para uma maior sustentabilidade da vida. No entanto, estar longe de ter atingido uma boa parte das trabalhadoras que compõe esse grupo tão diverso e marcado por desigualdades.

Em estudo com mulheres acampadas, Silva (2016) mostra a intensa desigualdade no campo e afirma que, ser incluída e visibilizada no âmbito público pode significar uma sobrecarga de trabalho, pois as mulheres continuam ocupando o lugar de submissão, desvalorização e invisibilidade nas atividades no âmbito privado, que são indispensáveis à unidade produtiva familiar, e chama atenção da necessidade de fazer o debate coletivo das relações de gênero.

Cabe reconhecer os avanços nos últimos 30 anos, frutos de reivindicações do MMC, especialmente a inserção da camponesa como segurada da previdência que alterou a condição de simples trabalhadora rural, reconhecendo uma identidade de agricultora bem como os esforços dos diversos movimentos sociais que tem como bandeira a equidade de gênero. Contudo, lembrar que a luta pela emancipação feminina continua sendo pauta.

\section{Trajetória da AMMCRS}

A AMMCRS, inscrição CNPJ 08.237.544/0001-83, foi fundada em setembro 2005 a partir de um trabalho de formação e conscientização sobre organização coletiva e participação na luta por direitos, realizado por duas mulheres militantes, Dona Antônia 
Maria Rodrigues e Dona Nucy Maria Rodrigues, que, à época, participavam do MMC representando o município Riacho Santana-Bahia.

Consta na primeira Ata da AMMCRS que o grupo teve início com 12 mulheres, debatendo direitos sociais, autonomia financeira, associativismo, créditos, produção e consumo de alimentos saudáveis, e combate à violência contra as mulheres que são temas que dialogam com os movimentos sociais de mulheres e EcoSol. O grupo deu início à formação de parcerias com órgãos do governo e do setor privado visando à qualificação das sócias tendo a agroecologia como vertente principal.

A AMMCRS tem sede própria localizada no centro da cidade - um sobrado com dois pavimentos, que proporciona boas condições de trabalho. No térreo situa-se escritório, sala de exposição dos produtos, sala para trabalhos manuais, almoxarifado e uma cozinha. A parte superior tem uma área espaçosa utilizada para reuniões, assembleias e confraternizações além de uma varanda.

Com a Associação formalizada foi possível acessar dois projetos para construção de cisternas de captação de água da chuva. Primeiro, a AMMCRS recebeu 70 cisternas do Centro de Agroecologia do Semiárido (Casa) ${ }^{5}$ para fortalecer a produção de hortaliças da comunidade Tanque de Claudiano que já estava produzindo para a Companhia Nacional de Abastecimento (Conab) ${ }^{6}$. No segundo projeto, o Assentamento Pau Sangue foi beneficiado com 25 cisternas pela Agência Nacional das Águas (Ana) ${ }^{7}$. Esses programas beneficiaram famílias e comunidades de forma direta e a AMMCRS indiretamente, visto que possuem sócias moradoras nessas comunidades.

A Associação produz e comercializa hortaliças, frutas, leguminosas, raízes, ervas medicinais; produtos elaborados como xaropes, doces e geleias, bolo de puba, brevidade, chimango, peta, farinha de mandioca, tapioca e trabalhos manuais como bordados e crochê.

A comercialização do excedente se dá na feira livre municipal, tendo início em 2007, a partir de um acordo de parceria, no qual duas ou mais mulheres ocupavam apenas uma única barraca, sendo cada uma responsável pelo transporte e venda de seus produtos. Essa prática deu certo por pouco tempo. Muitas mulheres desistiram do acordo alegando dificuldades com o transporte, disponibilidade de produtos, e até mesmo por acreditar que

\footnotetext{
${ }^{5,6}$ Sociedade civil de Utilidade Pública Municipal e Estadual sem fins econômicos, políticos e religiosos, que atua no semiárido baiano.

7 Agência reguladora criada pela Lei 9.984/2000 para atender objetivos e diretrizes da Lei das Águas do Brasil (Lei 9.433/1997).
} 
poderiam alcançar melhores oportunidades de lucro noutras formas de operação comercial. O transporte dos produtos e o acesso por estrada de chão continuam sendo um grande desafio para abastecimento no centro.

Após dez anos do início da comercialização na feira livre, em 2017, o município Riacho de Santana foi contemplado com uma Feira Permanente da Agricultura Familiar e a AMMCRS conquistou 20 barracas, que são ocupadas de forma compartilhada entre as agricultoras.

A comercialização para os mercados institucionais através do Programa de Aquisição de Alimentos (PAA) ${ }^{8}$ e o Programa Nacional de Alimentação Escolar (PNAE) ${ }^{9}$ representou um marco importante nas oportunidades de rentabilidade e melhoria das condições de vida das associadas, na redução de perdas de produtos e no aumento da produção de alimentos sob base ecológica. Nos primeiros projetos a AMMCRS gerenciava a entrega dos produtos às entidades beneficiadas mediante a Conab e com o passar do tempo a Secretaria de Assistência Social começou a coordenar a entrega dos alimentos diretamente ao grupo beneficiado. Os programas PAA e PNAE constituem um canal importante para garantir o acesso a uma alimentação adequada e atende, em parte, as medidas para combater o problema estrutural da fome no Brasil.

Cabe notar ainda que houve, à época, um incentivo do Instituto Regional da Pequena Agropecuária Apropriada (IRPAA) ${ }^{10}$ nos processos de capacitação nas áreas de produção (bolos, doces, geleias, compotas), embalagens e rotulagem, logísticas, planejamento da produção visando à regularização da entrega dos alimentos e formação para o consumo de produtos da agricultura familiar.

Desde as primeiras experiências a Associação ganhou crédito, conquistando novas sócias, que passaram a confiar na capacidade organizativa da mesma. Todas as políticas públicas mencionadas foram importantes para garantir mercado dos produtos agrícolas e alimentos saudáveis aos consumidores.

Como visto na trajetória da organização, as políticas públicas tiveram papel indispensável para o desenvolvimento do grupo. Dubeux e Batista (2107) também comentam que a política de apoio do governo aos agricultores para uma produção

\footnotetext{
${ }^{8}$ Instituído pelo Art. 19 da Lei no 10.696 , de 02 de julho de 2003.

${ }^{9}$ Lei no $^{\circ}$ 11.947/2009 e Resolução no 38/Fundo Nacional de Desenvolvimento da Educação -FNDE/2009.

${ }^{10}$ Organização Não Governamental que trabalha com soluções para convivência com o semiárido que respeitem as características do povo e das terras.
} 
ambientalmente sustentável se apresenta como fundamental na geração de trabalho e renda e ampliação do acesso a alimentos de boa qualidade, culturalmente adequados e preço acessível.

De acordo com Gattai e Bernades (2013), o “empoderamento" costumeiramente não emerge de forma espontânea entre comunidades pobres ou, quando ocorre, de maneira geral tem alcance limitado. A formação, fomento e apoio às comunidades desassistidas por agentes externos como a universidade, que atua por intermédio de projetos de extensão realizando treinamentos, palestras, consultorias, elaboração de projetos, trabalhos de pesquisa, como foi o caso da ação intervencionista desta pesquisa, contribuem com aquisição de conhecimentos e elaboração de conceitos necessários à gestão dos empreendimentos e fortalecimento dos coletivos de EcoSol.

Falando da necessidade de educação para contribuir com o fortalecimento da EcoSol enquanto uma prática social transformadora e emancipatória, Oliveira e Paiva (2016) destacam que os trabalhadores envolvidos com organização solidária, deparam-se cotidianamente com exigências cada vez mais complexas relacionadas à autogestão, busca da eficiência e viabilização das atividades econômicas, e, portanto, precisa-se combinar processos educativos integrados à elevação de escolaridade e outras iniciativas que contribuam para a formação política cidadã.

Apoiado na trajetória da Associação, que por sua natureza é um empreendimento no qual se vivencia as práticas da Ecosol, pode-se sugerir que o envolvimento com movimentos sociais de mulheres camponesas e seus processos favoreceram a mudança de perspectiva de mulheres que tinham uma vida limitada ao âmbito privado.

Lima e Jesus (2017) concordam que as ações protagonizadas por mulheres têm contribuído para ressignificar e valorizar as atividades de cuidados com a família, os mais velhos e doentes, com a horta, animais domésticos e plantas medicinais, que eram atividades invisíveis ou desprestigiadas enquanto práticas agrícolas e sociais por não possuir valor "monetário" identificado. Essa recolocação ajuda na ampliação das possibilidades de trabalho e renda, oferta de produtos locais e de melhor qualidade.

A experiência de um coletivo feminino não se resume ao aspecto econômico financeiro, apesar de ser motivo de grande utilidade para as trabalhadoras. Somente a renda não é suficiente, nem propósito derradeiro das lutas e práticas da EcoSol, que envolvem 
outra lógica de produzir alimentos, de relação com os bens naturais e de reproduzir modos de vida diferentes do convencional.

\section{Processos educativos nos espaços da prática com EcoSol}

As mulheres camponesas, organizadas no seu território, debatendo, reconhecendo direitos, tecendo relações, repensam seu cotidiano, criam novas possibilidades e buscam transformação de sua realidade, tendo seu chão como base. As práticas, vivências, conhecimentos gerados nos diversos espaços, tanto na Associação quanto na feira livre e festivais como nas relações estabelecidas com os consumidores, parceiros, poder público, pessoas da comunidade e do grupo familiar podem ser apontados como processos educativos ou possibilidades de aprendizados que auxiliaram para mudanças individual ou coletiva. Sobre conceitos de aprendizagem, Vygotsky (1998) e Freire (2005) remetem a processos libertadores que promovem o desenvolvimento da sociabilidade e possibilitam um fortalecimento na imagem que os grupos e indivíduos já possuem de si mesmos.

No começo da AMMCRS, apesar de moradoras e trabalhadoras do campo, poucas mulheres enxergavam na agricultura familiar uma oportunidade de trabalho e renda com capacidade de melhorar as condições de vida da sua família. D. Antônia, uma das fundadoras, relatou a necessidade do conhecimento para iniciar o trabalho com as mulheres: "a gente começou com a formação, reunindo para discutir a realidade. No primeiro projeto havia 12 mulheres, hoje, 114”. Gattai e Bernades (2013) confirmam que os grupos de EcoSol se fortalecem ao longo do tempo, e à medida que o processo de formação e fomento aos negócios solidários ocorrem, os grupos adquirem poder e autonomia econômica, cultural, social e política.

As mulheres entrevistadas reconhecem que a motivação para o trabalho público surgiu com o aprendizado gerado nos encontros promovidos pela AMMCRS e MMC. Como pode ser visto na fala da associada Edileusa Ferreira da Silva, da Comunidade de Tanque Claudiano:

Participar da Associação tem sido muito bom. Aprendi, me desenvolvi, passei a participar da sociedade, de cursos, de viagens. Antes não havia incentivo de ninguém. Não via como sair de casa, só cuidando dos meninos, indo para roça e mais nada. De primeiro a gente era mais "besta", sei lá, só se preocupava com a casa. Hoje ficamos mais inteligentes. Quando tem alguma atividade eu só falo com os meninos: toma conta aí que estou indo para Associação. 
O aprendizado adquirido com as atividades da AMMCRS contribuiu com o desenvolvimento individual da participante, ajudando a ter uma vida social, a ter mais confiança no seu saber, a buscar estratégias para organizar melhor e dividir as tarefas domésticas com os filhos e o marido. As práticas nos processos de EcoSol parecem ser espaços orientados nos conceitos de educação problematizadora de Freire (2005), pois desenvolvem a autoestima, o sentimento de pertencimento e o empoderamento dos grupos e de seus respectivos participantes.

Os percalços, conflitos e desafios diante da prática da autogestão possibilitaram alternativas para novos fazeres e novos aprendizados. Por exemplo, frente à escassez hídrica, as famílias passaram a se preocupar com as condições ambientais e agir de forma mais consciente, reduzindo o consumo e aproveitando melhor a água, fizeram reflorestamento, construíram poços tubulares e caixas de captação de água da chuva. Schmitt (2010) também relata que as experiências vivenciadas, nos empreendimentos solidários, por camponeses e agricultores familiares que atuam com agroecologia, apontam para estratégias criativas de mobilização de recursos, capacidades e vínculos, na produção de novas formas de organização do trabalho e de relação da atividade agrícola com os ecossistemas locais.

Com relação a formação no aspecto técnico, teve início o resgate do plantio com sementes crioulas, produção de hortaliças livres de veneno, uso de insumos da própria roça, que são bases para uma agricultura camponesa agroecológica em acordo com o modelo proposto pelo MMC. Boni (2013) explica que ao buscar a agroecologia, a proteção do ambiente e a recuperação de variedades de alimentos e de tradições esquecidas com a modernização da agricultura tem-se um modelo sustentável.

Maria Auxiliadora Pereira, moradora da comunidade de Santana, foi uma das pioneiras da AMMCRS e relata sobre seus 10 anos de associação:

Sou trabalhadora rural, produzo hortaliças e frutas. Não posso afirmar que são orgânicos porque não observo a vizinhança, mas são produzidos sem uso de veneno. A Associação tem proporcionado uma experiência muito boa. Acho tudo bom! As coisas que não são tão boas quando surgem a gente aprende a avaliar e melhorar. $\mathrm{O}$ que acho pior e me deixa triste é ver que algumas mulheres não dão muito valor ao que temos, acham que o movimento serve apenas para trabalhar e obter uma renda e as vezes se afastam quando o projeto acaba. Não veem como um apoio para tudo, para questões psicológicas, familiar. 
$\mathrm{Na}$ fala da trabalhadora nota-se clareza quanto ao valor de sua produção, resultado de seu trabalho, do aprendizado mesmo nas piores situações e das possibilidades do apoio psicológico que uma associação pode representar e sente por algumas mulheres não conseguirem perceber as inúmeras oportunidades além da renda.

A participação na Associação ajudou as mulheres a buscar estratégias para mudar a rotina no núcleo familiar e promoveu uma maior integração entre as famílias de uma mesma comunidade. Práticas consideradas tradicionais da cultura camponesa que estavam esquecidas a exemplo do mutirão foram resgatadas. Essas ações tendem a convergir para um mesmo ponto: o desenvolvimento pessoal, a melhoria das condições de vida da família e desenvolvimento do local em que vivem. Desenvolvimento local, nesse contexto, não deve ser entendido como objetivo final da Associação haja vista toda dinâmica existente no território que é um espaço delimitado por relações de poder. No entanto, sempre que empreendimentos solidários conseguem se estabelecer há ganhos por fortalecer a economia e a cultura local.

A AMMCRS se constitui como um lugar de possibilidades. Com as experiências da EcoSol, as mulheres conseguiram se organizar para produzir, e algumas delas começaram a participar de cursos, estudar, representar a Associação no território, noutros municípios e estados, viajar a passeio, combinar divisão das atividades domésticas, diminuindo assim o peso das tarefas que desempenham ao longo do dia.

Borges e Sguarezi (2012) comentam que a EcoSol é uma iniciativa que tem como espaço a micro-organização, o lugar de possibilidade de realização de ações, de eventos, de iniciativas e de projetos que promovam a transformação social, econômica, política e epistemológica visando a inclusão social. Mais que isso, os autores declaram que o movimento de EcoSol representa uma oportunidades de construção de projetos econômicos, sociais e pedagógicos que rompem com os padrões de conhecimento, de valores e de práticas hegemônicas na sociedade capitalista, quando se pode demonstrar a relevância social da solidariedade, da fraternidade, da cooperação e da autogestão.

O grupo acredita que a experiência com os novos papéis assumidos e suas responsabilidades ajudou no fortalecimento dos vínculos e numa melhor preparação para o enfrentamento de situações adversas, o que tem acordo com Singer (2002) ao mencionar que a prática da autogestão tem como mérito principal, o desenvolvimento humano, além 
do aspecto econômico, a participação das discussões e decisões do coletivo, educa e conscientiza, tornando a pessoa mais realizada, autoconfiante e segura.

Pode-se dizer, considerando a dimensão e contexto deste trabalho, que a AMMCRS colaborou com mudanças nas condições de vida das famílias, contribuiu com a integração entre famílias nas comunidades, no processo de combinação para mudança de rotina no núcleo familiar, nas oportunidades para qualificação e para participação de atividades sociais, além de ter ajudado no reconhecimento do trabalho das mulheres. Evidente que, numa sociedade marcada por desigualdades, hierarquização e negação de acesso, ainda há muito a ser conquistado para manter e para dar continuidade à luta pela consolidação do empreendimento, garantir políticas públicas de apoio à produção e comercialização e a conquista de autonomia.

\section{Aprendizados gerados a partir das ações da pesquisa-ação}

As ações de intervenção foram estabelecidas coletivamente após discussões tentando encontrar uma alternativa que pudesse conciliar as necessidades da AMMCRS com interesses do grupo. De um lado, a Associação dispunha de potencial produtivo e organizacional, boa capacidade de articulação com outros movimentos e coletivos, além de uma clientela em formação. Do outro lado, havia necessidade de aprimorar o processo de produção dos alimentos quanto à tecnologia de processamento, embalagem e rotulagem e carência de assistência técnica, consultoria no território, além da dificuldade, por parte das sócias, de acesso a ferramentas como computador e celular, pela falta de domínio dessas tecnologias, baixa escolaridade da maioria e limitação com conexão internet.

Um curso de capacitação com aulas práticas para atender prioritariamente as manipuladoras de alimentos visando melhorar a qualidade dos fabricados, foi considerada a demanda mais urgente e possível de ser realizada na ocasião. A motivação teve relação com as últimas conquistas da Associação - contemplada com uma cozinha industrial e um espaço permanente no mercado municipal para implantação da feira da agricultura familiar por meio de Edital do Bahia Produtiva - projeto do governo do Estado.

O conteúdo da capacitação incluiu manipulação higiênica e normas de segurança dos alimentos, métodos de conservação, diversificação da produção, uso adequado e seguro dos utensílios, exigências legais para apresentação do produto no mercado. 
"Quero colocar em prática a fabricação de compotas que aprendi a fazer" (Edileusa Ferreira da Silva). "Achei muito interessante. Junto com as companheiras vamos colocar em prática o beneficiamento das frutas do mesmo jeito que foi ensinado" (Luziene dos Santos Lima). "Gostaria de mais cursos, de outras coisas. Se perde muitos legumes porque os maiores vão para entrega e os menores, também de boa qualidade, são desperdiçados" (Maria Auxiliador Pereira Dias). O teor dos relatos sugere que houve interesse por parte das participantes na aplicação dos conhecimentos para melhoria dos processos produtivos.

Constatou-se, tempos depois, à época da primeira feira, que os produtos elaborados e dispostos à venda estavam com uma melhor apresentação, devidamente embalados e rotulados, constando o selo da agricultura familiar, nome da marca, o que ajudou a dar maior visibilidade dos produtos e melhor aceitação por parte dos consumidores.

Agentes externos como poder público, instituições de ensino e organizações não governamentais podem ajudar as associações com inserção de ferramentas técnicas e gerenciais, que são essenciais no circuito mercantil, garantindo a viabilidade econômica do empreendimento. Sobre a contribuição das instituições de ensino, Cunha (2002) afirma que podem desempenhar um papel importante no empoderamento dos grupos quando auxilia na elaboração de projetos, na capacitação técnica e organizacional, no apoio à captação de recursos financeiros.

Levando em consideração a vida pregressa da mulher do campo, é possível afirmar que houve um salto positivo em diversos aspectos. Mudanças aconteceram, no entanto, para atingir melhores resultados ainda se faz necessário ampliar o acesso dessa mulher e seus familiares à educação, que aqui deve ser entendido como uma educação emancipadora, conforme os conceitos de Freire (2005) - aquela que possibilita saber refletir sobre a realidade, percebendo-se como sujeitos históricos que podem se posicionar, emitir opiniões, fazer escolhas, construir rumos para suas vidas.

Nessa linha de raciocínio, Oliveira e Paiva (2016) afirmam que a EcoSol, sob os princípios da solidariedade e autogestão, contribui para um país mais justo e solidário, mas, a emancipação depende dos níveis de consciência do indivíduo, da sensibilidade aos problemas, da capacidade de construir utopias reais e da dimensão do sentido interior que mobiliza e impulsiona as pessoas.

Para terminar, dizer que a pesquisa-ação teve uma contribuição no processo socioeducativo, não obstante os créditos da educação promovida nos espaços dos 
movimentos sociais de mulheres e da Ecosol. Espaços esses que sempre se ampliam, renovam e atualizam tentando a sobrevivência de trabalhadores (as) numa sociedade de economia capitalista e marcada por tamanha desigualdade social e de gênero.

\section{CONSIDERAÇÕES FINAIS}

A experiência das camponesas da AMMCRS com as práticas da EcoSol e os desdobramentos advindos dela, considerando as limitações individuais, do grupo e do município, ajudou a proporcionar, de certa maneira, avanços nas diversas formas de desenvolvimento, autorrealização, interesse por participação e maior engajamento político, reconhecimento da viabilidade econômica da organização, visibilidade, geração de renda, formação cidadã e o despertar de um sentimento de pertencimento ao local. Essas conquistas podem sinalizar uma leve fissura na ligação com o espaço doméstico e não reconhecido para uma situação capaz de melhorar seu bem-estar e aumentar sua interação com a comunidade.

Acredita-se que o principal componente com a experiência foi despertar no indivíduo e no grupo a percepção da existência de outras e de novas possibilidades de sobrevivência com o desenvolvimento de trabalhos coletivos, o que se resume no maior ganho das organizações que caminham com a EcoSol.

O trabalho do movimento de mulheres e as interferências externas que ocorreram à época como exemplo as políticas públicas por meio dos projetos sociais, tiveram forte contribuição no apoio ao desenvolvimento da Associação. Entretanto, o reconhecimento do trabalho das mulheres como importante para o desenvolvimento local não deve ser encarado como fim para uma sociedade marcada por negação de acessos ao povo pobre, mas sim como um começo para a busca da emancipação da mulher camponesa, principalmente no atual contexto, que se apresenta desfavorável para agricultura familiar, quando se exige um maior esforço para fortalecer as organizações da sociedade civil e para promover uma articulação dos movimentos sociais sob orientação dos princípios da EcoSol e fortalecimento mútuo.

\section{REFERÊNCIAS}

BONI, V. Movimento de mulheres camponesas: um movimento camponês e feminista. Grifos, Chapecó, v. 22, n. 34/35, p. 67-88, 2013. Disponível em: 
https://bell.unochapeco.edu.br/revistas/index.php/grifos/article/view/1259. Acesso: 28 jun. 2020.

BORGES, J. B.; SGUAREZI, S. B. Economia solidária e educação. Akrópolis, Umuarama, v. 20, n. 3, p. 151-158, jul./set. 2012.

CABRAL, S. M. Economia solidária: um processo educativo. Prâksis, Novo Hamburgo, v. 1, p. 27-31, 2005. Disponível em:

https://periodicos.feevale.br/seer/index.php/revistapraksis/article/view/538/468. Acesso: 20 fev. 2019.

CARDOSO, E. M.; RODRIGUES, V. S. Mulheres construindo a Agroecologia no Brasil. Agriculturas, Rio de Janeiro, v. 6, n. 4, p. 12-16, dez. 2009.

CUNHA, G. Economia solidária e políticas públicas: reflexões a partir do caso do programa incubadora de cooperativas da prefeitura municipal de Santo André, SP. 2002. 163 f. Dissertação (Mestrado em Ciências Sociais) - Faculdade de Ciência Política, Universidade de São Paulo, São Paulo, 2002.

DUBEUX, A.; BATISTA, M. P. Agroecologia e Economia Solidária: um diálogo necessário à consolidação do direito à soberania e segurança alimentar e nutricional. Redes, Santa Cruz do Sul, v. 22, n. 2, maio/ago. 2017. Disponível em:

https://online.unisc.br/seer/index.php/redes/article/view/9340. Acesso: 20 jun. 2020.

FERNANDES, O. As mulheres do campo. Princípios, São Paulo, n. 11, p. 33-37, ago. 1985. Disponível em: http://revistaprincipios.com.br/artigos/11/cat/2085/as-mulheres-docampo-.html. Acesso: 02 jul. 2019.

FREIRE, P. Pedagogia do Oprimido. 14. ed. Rio de Janeiro: Paz e Terra, 2005.

GAIGER, L. I. Os caminhos da economia solidária no Rio Grande do Sul. Revista Crítica de Ciências Sociais, Coimbra, n. 79, p. 57-77, 2007.

GATTAI, S.; BERNARDES, M. A. Papel e responsabilidades da universidade no processo socioeducativo presente em movimentos de economia solidária. Rev. Adm. Mackenzie, São Paulo, v. 14, n. 6, p. 50-81, nov./dez. 2013. Disponível em: http://www.scielo.br/pdf/ram/v14n6/04.pdf. Acesso: 30 jul. 2019.

IBGE. Riacho de Santana. Brasília: IBGE, 2010. Disponível em: https://cidades.ibge.gov.br/brasil/ba/riacho-de-santana/panorama. Acesso: 20 ago. 2020.

LAVILLE, J. L.; GAIGER, L. I. Economia solidária. In: CATTANI, A. D.; LAVILLE, J. L.; GAIGER, L. I.; HESPANHA, P. (org.). Dicionário internacional da outra economia. Coimbra: Almedina, 2009. p. 7-47.

LECHAT, N. M. P. As raízes históricas da Economia Solidária e seu aparecimento no 
Brasil. In: SINGER, P. (org.). Economia Solidária. [S.1.: s.n.], 2002. v. 1. p. 4-17. Disponível em: http://retosalsur.org/wp-content/uploads/2013/09/Econom\%C3\%ADaSolidaria-Volume-1.pdf. Acesso: 30 ago. 2019.

LIMA, M.; JESUS, V. Questões sobre gênero e tecnologia na construção da agroecologia. Scientiae Studia, v. 15, n. 1, p. 73-96, jun. 2017. Disponível em: http://www.revistas.usp.br/ss/article/view/133644. Acesso: 20 jun. 2020.

OLIVEIRA, A. A. R.; PAIVA, M. M. O movimento da economia solidária e suas diretrizes educativas. Holos, Natal, v. 32, n. 5, p. 33-45, 2016.

QUEM somos. In: MOVIMENTO de Mulheres Camponesas. [Brasília, 20--?]. Disponível em: http://www.mmcbrasil.com.br/site/node/43. Acesso: 02 maio 2020.

SCHMITT, C. J. Economia solidária e agroecologia: convergências e desafios na construção de modos de vida sustentáveis. Boletim Mercado de Trabalho: conjuntura e análise, n. 42, p. 55-64, fev. 2010. Disponível em:

https://www.ipea.gov.br/portal/images/stories/PDFs/mercadodetrabalho/08_Eco_02_conver gencias.pdf. Acesso: 24 jun. 2020.

SILVA, F. R. F. Gênero, agroecologia e economia solidária: estudo de caso do grupo de mulheres do Acampamento Recanto da Natureza em Laranjeiras do Sul - PR. Desenvolv. Meio Ambiente, v. 39, p. 115-132, dez. 2016. Disponível em: https://revistas.ufpr.br/made/article/view/45697. Acesso: 26 maio 2020.

SINGER, P. Introdução à economia solidária. São Paulo: Fundação Perseu Abramo, 2002.

THIOLLENT, M. Metodologia da pesquisa-ação. 4. ed. São Paulo: Cortez, 1988.

TYGEL, D. O que é Economia Solidária. In: CIRANDAS. Brasília, 04 mar. 2011. Disponível em: https://cirandas.net/fbes/o-que-e-economia-solidaria. Acesso em: 30 ago. 2019.

VERGARA, S. C. Métodos de pesquisa em administração. São Paulo: Atlas, 2005.

VYGOTSKY, L. S. Formação social da mente. 6. ed. São Paulo: Martins Fontes, 1998. 